\title{
FDA finally begins collecting user fees
}

\section{FDA expects}

to collect about

$\$ 36$ million in

fees to use in hiring staff.
WASHINGTON, D.C.-With a collective sigh of relief, officials of the Food and Drug Administration (FDA, Bethesda, MD) say they are ready to start implementing a userfee program authorized by Congress last year. Agency officials will send out dozens of invoices to companies, expecting to collect about $\$ 36$ million in fees to use in hiring staff and accelerating new product reviews. The agency will collect one-time fees for new drug applications, retroactive to September 1992, and annual fees for manufacturing facilities and marketed products. Revenues from user fees are projected to reach $\$ 84$ million by 1997 .

Until this summer, when a supplemental appropriation from Congress was passed, FDA could not turn the user-fee program into reality. However, the agency has not

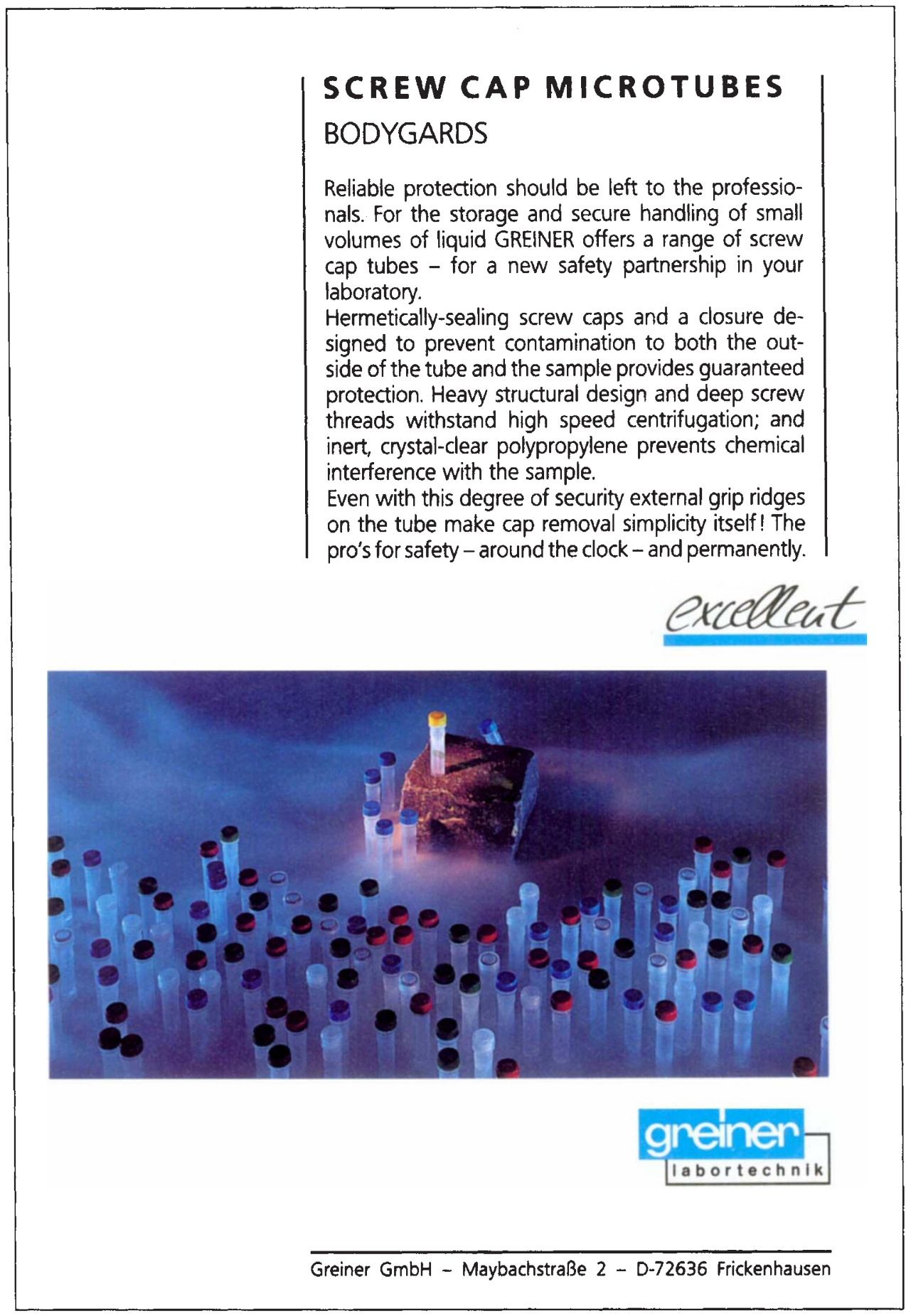

